\title{
Considerations for Accurate Whole Plant Photosynthesis Measurement
}

\author{
Noriko TAKahashi, Peter P. Ling and Jonathan M. Frantz* \\ Department of Food, Agricultural and Biological Engineering, The Ohio State University/ \\ Ohio Agricultural Research and Development Center, 1680 Madison Avenue, Wooster, OH44691, U.S. \\ *USDA, ARS, Application Technology Research Unit, 2801 W. Bancroft, Mail Stop 604, Toledo, OH43606, U.S.
}

(Received May 23, 2008)

\begin{abstract}
Whole plant carbon exchange rate (CER) measurements provide an integral assessment of how an entire plant responds to biotic and abiotic factors. CER determination is based on measurements of $\mathrm{CO}_{2}$ uptake and release that can be determined using various types of systems including Closed, Semi-closed, and Open systems. This review focused on important design and operational considerations of Open CER measurement systems. Primary mechanical and biological factors that may influence measurement accuracy including chamber leakage, $\mathrm{CO}_{2}$ differential between air inlet and outlet of a chamber, chamber air humidity, canopy air speed, acidity of growth media, and irrigation water to name a few. Proper design and operation of a whole canopy photosynthesis system are necessary to assure accuracy of the CER measurements that may be used to assess both short-term responses and long-term yield of a plant as a result of given stimuli.
\end{abstract}

Keywords : assimilation chamber, carbon exchange rate, gas exchange, non-destructive measurement, plant monitoring

\section{INTRODUCTION}

An understanding of a plant's response to the environment is important for the prediction of its growth and development. Because any organ that contains chloroplasts in plants can contribute to plant production with photosynthesis and all plant tissue respires constantly, carbon exchange rate (CER) measurement is used for quantifying the effects of environmental changes on the productivity of plants, or for determining the final yield (Šesták et al., 1971; Monje and Bugbee, 1998).

Commercially available CER measurement systems are widely adopted for leaf level measurements. Poor relationships, however, were reported between leaf CER and dry matter production, as well as yield (Elmore, 1980; Evans, 1993). Reasons for this poor relationship include factors such as the measured leaf may not be representative of the whole plant, and it does not account for the $\mathrm{CO}_{2}$ exchange that occurs in plant roots, shoots, meristems, and stems. An estimated 70 to $85 \%$ of total respiration occurs in unmeasured roots, stems, and meristems were reported (Frantz et al., 2004).

There are other differences between leaf and canopy gas exchange. Net photosynthesis (Pn)

Corresponding author: Noriko Takahashi, fax : +1-330-263-3670,

e-mail : takahashi.34@osu.edu 


\section{N. TAKAHASHI ET AL.}

of single leaves typically show much lower light compensation points and tend to light-saturate at lower light in comparison to the whole stands (Wheeler et al., 2003). Pn of single leaves was at a higher CER than that of the whole plant (on a per leaf area basis) when comparisons were made at the same $\mathrm{CO}_{2}$ concentration (Leonardos et al., 1994). The lower whole plant Pn was primarily due to mutual shading and respiratory activity of sinks. Further complicating single leaf measurements is the fact that stomata sometimes do not open uniformly across the leaves (Terashima et al., 1988) leading to Pn variability across a single leaf.

To bridge the single leaf measurements and the whole plant canopy assessment, many models were reported, including that of Boote and Loomis (1991), Norman and Arkebauer (1991), and Amthor (1994). These models, however, have only been validated over a limited range of conditions and many require additional, time-consuming measurements. Furthermore, leaf CER measurements can be intrusive possibly altering canopy architecture thereby inducing measurement artifacts. A non-contact, non-intrusive measurement system is desirable for more precise quantification of plant responses to stimuli at the whole plant level.

Whole plant CER measurements can better predict the final yield than that obtained from single leaf CER. Zelitch (1982) reported that many investigations showed a clear positive correlation between whole canopy. For example, carbon gain determined by conventional chemical analysis was in close agreement with estimates of carbon gain measured using whole canopy with accuracies reported to be between 92-107\% (Dutton et al., 1988), 85-99\% (Bate and Canvin, 1971), and 102.8 $\pm 4.7 \%$ (Monje and Bugbee, 1998). Recently, Katsura et al. (2006) also reported excellent rice biomass yield prediction using CER measurements collected from a multi-channel whole canopy chamber system. Besides predicting final yield, whole canopy CER is a better measurement of short-term plant response to the stimuli than that obtained from single leaf CER. For example, whole canopy CER measurements were more effective in detecting phytotoxicities caused by insecticide (Klingeman et al., 2000), and fungicide (van Iersel and Bugbee, 1997). van Iersel and Bugbee (2000) warned, however, that short-term CER measurements, even those made at the whole plant or canopy level, can have poor correlation with long-term plant growth. Many factors, including design of the chambers, operation of the chamber, and physiological unknowns could have contributed in the poor correlation.

While stock leaf CER measurement instruments are commercially available and widely adopted, most whole plant CER measurement instruments are custom designed and constructed. To assure accurate whole plant CER measurements, individual designers must consider design, construct and operation of the systems carefully. Valuable gas exchange measurement considerations are well documented in a series of paper as a result of a 1989 American Society of Horticultural Scientists (ASHS) workshop on gas exchange measurements (Bugbee, 1992; Mitchell, 1992; Wheeler, 1992). Since that time, the cost of reliable $\mathrm{CO}_{2}$ sensors has greatly decreased, yet no commercial whole-plant gas exchange system is available. With the advances of molecular biology tools in the last 20 years and the adaptation of small model plants (such as Arabidopsis thaliana and dwarf crops), the value of incorporating gas exchange as a laboratory technique is still great.

The objectives of this study were to review design of assimilation chambers for whole canopy CER measurements and to compile a set of operational guidelines to improve their measurement accuracy.

\section{WHOLE PLANT PHOTOSYNTHESIS MEASUREMENT SYSTEMS}

The whole plant CER measurement systems may be classified into three types; i) Closed, ii) Semi-closed, and iii) Open (Coombs et al., 1985; Bugbee, 1992; Mitchell, 1992). Some major differences among the three types are the design of its assimilation chamber, which the plant is 


\section{PHOTOSYNTHESIS MEASUREMENT}

enclosed to facilitate the measurement of CER, and how carbon exchange is determined. Closed system can be used for the short-term CER measurement, whereas Semi-closed and Open system can be used for the long-term measurement.

i) Closed system

A Closed system is easy to operate, low cost to construct, and suitable for short-term, transient response measurements. Photosynthesis can be determined from the depletion rate of $\mathrm{CO}_{2}$ in the chamber or respiration as an increase in $\mathrm{CO}_{2}$. Closed systems have been used for rapid canopy measurements. The $\mathrm{CO}_{2}$ concentration inside the chamber changes rapidly after closure, that makes long-term measurements impractical. Closed systems cannot provide true steady-state measurements because stomatal aperture may take up to an hour to respond completely to small changes in ambient $\mathrm{CO}_{2}$ and this significantly influences the estimate of Pn (Šesták, et al., 1971). Thus, a Closed system is generally not suitable for experiments that explore the responses of photosynthesis to a range of environmental conditions. In addition, an important disadvantage of this type of systems is its difficulty to achieve zero leakage. Sealing a chamber to prevent outward and inward leaks is simple in principle but challenging to implement. An air-tight seal is critical for a Closed system because the calculations explicitly assume that the plant is exchanging gases with a fixed volume of air and any leak weakens that assumption. Thus, procedures are needed for the determination of the leakage rates (Bugbee, 1992).

Typical $\mathrm{CO}_{2}$ data collected using this system would be an exponential decrease to some constant value (Fig. 1A). That value is an equilibrium reached by the balance between the leakage rate of outside $\mathrm{CO}_{2}$ into the chamber and the photosynthetic rate at that low $\mathrm{CO}_{2}$ concentration. To calculate photosynthetic rate, chamber volume is multiplied by the change in $\mathrm{CO}_{2}$ per time period and divided by the surface area of the leaves or ground (Fig. 1B).

ii) Semi-closed system

This type of system is less sensitive to transient, short-term fluctuations in CER as the Closed systems, and can be used for long-term monitoring purposes. Photosynthesis and respiration are measured from the amount of $\mathrm{CO}_{2}$ added or removed to maintain a $\mathrm{CO}_{2}$ set point of the system during a certain time period, respectively. An example of $\mathrm{CO}_{2}$ addition to maintain the set point when photosynthesis was active, and additional $\mathrm{CO}_{2}$ generated as a result of respiration during a 48-h cycle for a stand of soybeans grown with a 12-h photoperiod is shown in Fig. 2 (Wheeler, 1992).

Functionalities of Closed and Semi-closed systems can also be combined into one. Wheeler (1992) reported a hybrid system that can function as both a Closed system and a Semi-closed system to collect both short-term and continuous diurnal changes in photosynthesis. Similar to Closed systems, chamber leakage has significant effect on accuracy of CER measurements.

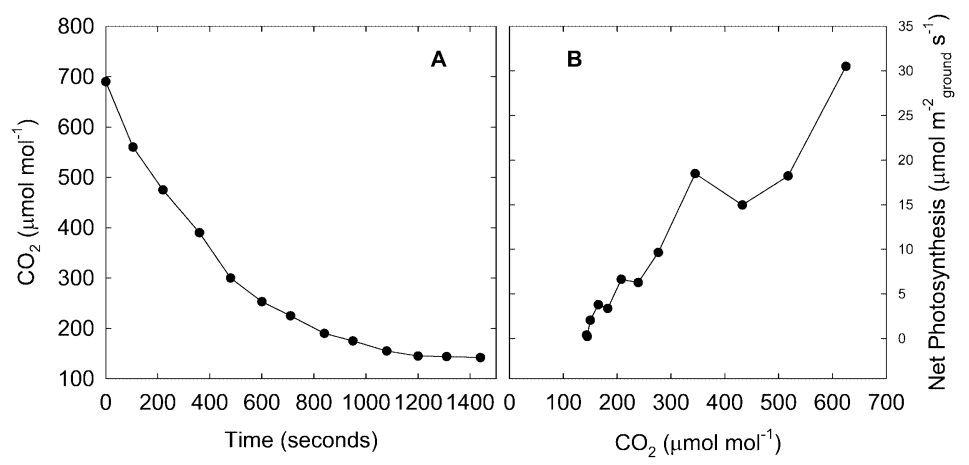

Fig. $1 \mathrm{CO}_{2}$ decrease in a Closed system containing wax beans (Phaseolus vulgaris) (A) and that plant's resulting photosynthetic rate $(\mathrm{B})$. 

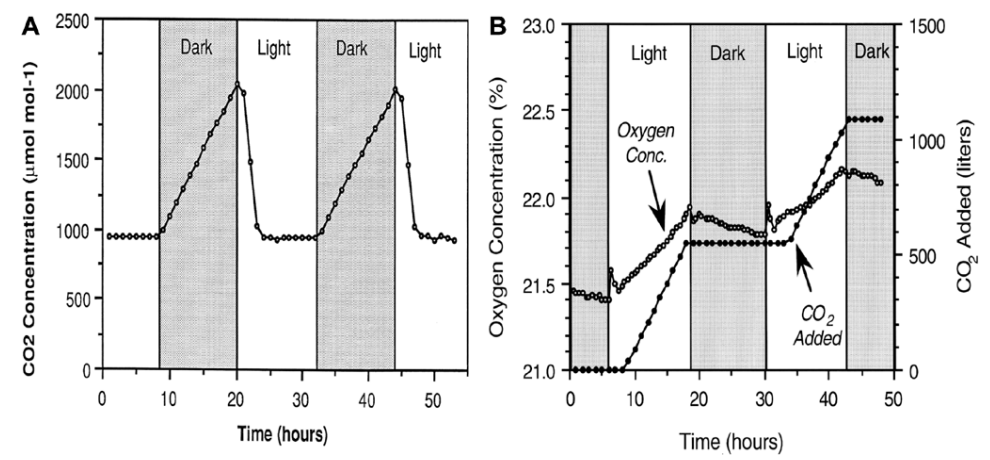

Fig. 2 A Semi-closed system uses amount of $\mathrm{CO}_{2}$ added or need to be removed from a chamber to maintain a set point to determine photosynthesis and respiration, respectively. The line labeled " $\mathrm{CO}_{2}$ added" shows amount of external $\mathrm{CO}_{2}$ added to the system (A). The $\mathrm{CO}_{2}$ increases during time periods 8-20 $\mathrm{h}$, and $32-44 \mathrm{~h}$ are results of respiration (B). These two figures were adopted from Wheeler (1992) with permission.

Air leakage has significant influence on the accuracy of CER measurement in a Semi-closed system. Acock and Acock (1989) found that the air leakage produced 5\% to 14\% error in estimating CER in a Semi-closed system chamber, thus the total leakage rates must be included in the final yield estimation using the continuous CER measurement (Wheeler, 1992). Leakage rates must be precisely determined and verified to assure accurate measurement of CER. Generally, chamber leakage is measured before and/or after an experiment in the absence of plants. As tracer for estimating chamber leakage with plants, $\mathrm{CO}_{2}$ is easily measured with the same equipment to monitor photosynthesis and respiration. However, leakage can only be estimated when plant and soil respirations are stable because a change in ambient $\mathrm{CO}_{2}$ alters the $\mathrm{CO}_{2}$ gradient between the chamber atmosphere and ambient air and this in turn changes chamber leakage (Kimball, 1990). To estimate the chamber leakage rate without assumptions about respiration rate and problems arising from using chambers in $\mathrm{CO}_{2}$, Tingey et al. (2000) used sulfur hexafluoride $\left(\mathrm{SF}_{6}\right)$, and Baker et al. (2004) described a nitrous oxide $\left(\mathrm{N}_{2} \mathrm{O}\right)$ leak quantification system. $\mathrm{N}_{2} \mathrm{O}$ can be used for the leakage estimation because both $\mathrm{CO}_{2}$ and $\mathrm{N}_{2} \mathrm{O}$ have the same molecular weight which would cause these two gases to have the identical molecular diffusivity. $\mathrm{N}_{2} \mathrm{O}$ is highly soluble in water condensed in the chamber system, whereas $\mathrm{SF}_{6}$ has the lowest water solubility for any gas (Tingey et al., 2000). $\mathrm{N}_{2} \mathrm{O}$ could be used to accurately and reliably estimate chamber leakage rates when it is necessary to maintain specific chamber $\mathrm{CO}_{2}$ treatment set points.

iii) Open system

CER of an Open system is determined from $\mathrm{CO}_{2}$ differential between the air entering and leaving the chamber. It allows for continuous monitoring of photosynthesis and respiration with good accuracy without leakage considerations.

Open systems are typically operated with an input air to the chamber greater than the leakage or sampling rate, thus maintaining a slightly pressurized chamber. This positive pressure causes most leaks to be in the outward directions. Outward leakage has no effect on estimated CER assuming the flow rate of air entering the chamber is accurately measured and the flow rate into the chamber is larger than the leakage rate. Accurate measurement of the inlet air mass flow rate is essential because of an error of the flow rate results in a large error in the estimate of photosynthesis (Long, 1985).

Typical data collected using this type of system would be constant or nearly constant $\mathrm{CO}_{2}$ concentration within a chamber (Fig. 3A). A CO 2 differential (see below) is measured as the difference 


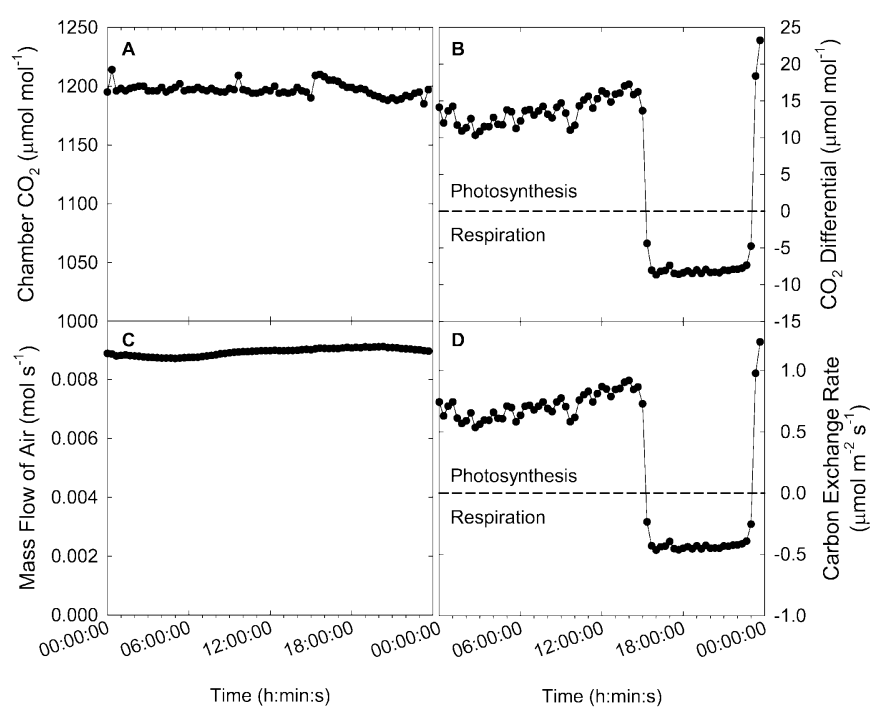

Fig. 3 Carbon exchange rate of a lettuce canopy grown in elevated $\mathrm{CO}_{2}$ inside a growth chamber. A nearly constant $\mathrm{CO}_{2}$ environment (A) can be achieved while still having a significant positive or negative $\mathrm{CO}_{2}$ differential (B). If accurate measurements of the mass of air flowing into the chamber are made (C), the product of the $\mathrm{CO}_{2}$ differential and mass flow of air results in the carbon exchange rate (D).

between the supply air and the air that is sampled from the chamber (Fig. 3B). This value is multiplied by the mass of air flowing into the chamber (Fig. 3C) to calculate the CER; positive values are photosynthesis and negative values are respiration (Fig. 3D).

Majority of the whole plant photosynthesis systems found in the literature are Open systems probably due to its advantages over Semi-closed systems such as simplicity to construct and robustness against measurement error resulting from chamber leakage, and long-term monitoring advantages over Closed systems. The remaining discussion will continue on the design and operation of the Open systems.

\section{PHOTOSYNTHESIS MEASUREMENT USING AN OPEN SYSTEM}

Figure 4 depicts a schematic diagram of an Open whole-canopy photosynthesis measurement system. As shown in Equation (1), CER is determined from measurements of air mass flow rate, and $\mathrm{CO}_{2}$ differential between the inlet and the outlet of the chamber as follows (Šesták et al., 1971):

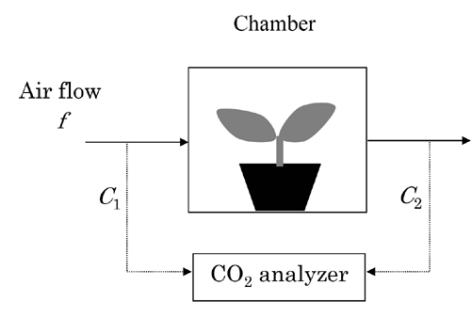

Fig. 4 Schematic diagram of photosynthesis measurement system in an Open system. $f$ is air mass flow rate through the chamber $\left[\mathrm{mol} \mathrm{s}{ }^{-1}\right], C_{1}$ and $C_{2}$ are $\mathrm{CO}_{2}$ concentrations at the inlet and the outlet $[\mu \mathrm{mol}$ $\mathrm{mol}^{-1}$, respectively. 


\section{N. TAKAHASHI ET AL.}

$$
C E R=f\left(C_{1}-C_{2}\right) / A
$$

where $f$ is air mass flow rate through the chamber $\left[\mathrm{mol} \mathrm{s}^{-1}\right], C_{1}$ and $C_{2}$ are $\mathrm{CO}_{2}$ concentrations at the inlet and the outlet $\left[\mu \mathrm{mol} \mathrm{mol}^{-1}\right]$, respectively. $A$ is total leaf area of the canopy, or surface area of the chamber $\left[\mathrm{m}^{2}\right]$.

\section{MECHANICAL FACTORS INFLUENCING PHOTOSYNTHESIS MEASUREMENT}

Proper operation of a CER measurement system is key to acquire accurate and reliable data for photosynthesis determination. Researchers have suggested considering the following mechanical parameters to avoid measurement artifacts.

\section{Positive chamber pressure}

Leakage of outside air into a chamber could cause measurement artifact when a $\mathrm{CO}_{2}$ differential exists. The system must be slightly pressurized so that all leaks flow from inside to outside. A positive pressure range of $1 \mathrm{~mm}$ of water (Bugbee, 1992) to $10 \mathrm{~mm}$ of water (Field et al., 1989) was reported. Required air flow rate to maintain a certain positive pressure in the chamber depends on the leakage rate of the chamber. It is important be aware that zones of air pressure may be lower than that of outside the chamber even the chamber is slightly pressurized. For example, zone immediately behind a circulation fan has negative air pressure. A fan in the chamber should be placed away from any location that may leak.

\section{Considerations for $\mathrm{CO}_{2}$ differential and air flow}

As CER is determined from the product of the air flow and the $\mathrm{CO}_{2}$ differential of the chamber, accurate measurements of the both are essential. As high signal to noise ratio improves accuracy of data collection large $\mathrm{CO}_{2}$ differential and large air flow rate are desirable. While there is a negative correlation between the flow rate and the $\mathrm{CO}_{2}$ differential exists (Whiting and Lang, 2001), e.g. larger air flow rate causes low $\mathrm{CO}_{2}$ differential, and small air flow rate leads to larger $\mathrm{CO}_{2}$ differential, proper system design should take into account of both sensor specifications and chamber operation protocol related to inlet air flow rate and $\mathrm{CO}_{2}$ differential range regulations.

A range of $\mathrm{CO}_{2}$ differential between inlet and outlet of an Open chamber system should be maintained for proper measurement of CER. The low end of the range should be high enough for the $\mathrm{CO}_{2}$ analyzer to resolve the signal accurately. The higher side of the range should be low enough so that photosynthetic rate of the subject plant in the chamber is not artificially reduced due to limited $\mathrm{CO}_{2}$ supply (Šesták et al., 1971; Aoki, 1997). Even though high differential is desirable to improve $\mathrm{CO}_{2}$ sensing reliability, however, it may artificially affect photosynthesis of the plant in the chamber thus creates a measurement artifact. On the other hand, sensing very low $\mathrm{CO}_{2}$ differential requires extremely high resolution $\mathrm{CO}_{2}$ analyzer that could be cost prohibitive for some applications. Cost range of $\mathrm{CO}_{2}$ analyzers is from $\$ 2,000$ to 15,000 for resolution of $\pm 10 \mu \mathrm{mol}$ $\mathrm{mol}^{-1}$ and $\pm 1 \mu \mathrm{mol} \mathrm{mol}^{-1}$, respectively. Air mass flow meters cost from $\$ 250$ to $\$ 2,500$ for a range of resolution from $\pm 2.5 \%$ to $\pm 1 \%$ of full scale of reading. Higher $\mathrm{CO}_{2}$ differential with higher resolution air mass flow sensing system may help to relax resolution requirements of the $\mathrm{CO}_{2}$ analyzer selection for a more economical system.

For reliable CER determination, quality data of $\mathrm{CO}_{2}$ differential and air mass flow rate data are essential. As the fidelity of the data is affected by both signal level and sensor resolution, including operation range of $\mathrm{CO}_{2}$ differential and air mass flow rate is desirable for documenting CER measurement effort using an Open system. While some researchers did include the $\mathrm{CO}_{2}$ differential information in their reports, many did not. Table 1 provides some $\mathrm{CO}_{2}$ differential range and matching sensor resolution information found in the literature.

Effect of water vapor

Water vapor could affect CER measurement in more than one way. Dilution of the $\mathrm{CO}_{2}$ 
Table 1 Reported $\mathrm{CO}_{2}$ differential between the inlet and the outlet of the chamber for photosynthesis measurement in Open system.

\begin{tabular}{cc}
\hline References & $\mathrm{CO}_{2}$ differential $\left(\mu \mathrm{mol} \mathrm{mol}^{-1}\right)$ \\
\hline Bate and Canvin (1971) & $<30$ \\
Šesták, et al. (1971) & 20 \\
Mitchell (1992) & a few \\
Miller et al. (1996) & 15 to 35 \\
Aoki (1997) & 20 to 30 \\
Poni et al. (1997) & $<40$ \\
Whiting and Lang (2001) & 15 to 20 \\
Pena and Terara (2004) & 12 \\
\hline
\end{tabular}

concentration in the chamber by transpired water from the plants leads to appreciable errors in calculation of CER. Penning de Vries et al. (1984) found that the effect of the water vapor dilution on CER was 6 to $14 \%$ and the error in CER was proportional to transpiration rate of the plants. To rectify the effect of transpiration on the CER determination, relative humidity in the chamber could be maintained.

Water vapor could also affect infrared $\mathrm{CO}_{2}$ analyzer measurements. When an infrared gas analyzer is used for the $\mathrm{CO}_{2}$ measurement, it is essential to assure that the sample air is dry because the water vapor absorbs infrared radiation in a wavelength that coincides with the wavelength in which $\mathrm{CO}_{2}$ absorbs (Samish, 1978). Generally the moisture can be effectively removed from the gas samples by running the sample lines through a refrigerated water trap (Baker et al., 2004), by using a cooling coil (van Iersel and Bugbee, 2000), or a chemical desiccant. Bugbee (1992) pointed out that desiccants must be replaced at regular intervals, which is inconvenient for longterm studies. Some instruments have a compensate function for humidity (model GMP343, Vaisala, Helsinki, Finland). Other $\mathrm{CO}_{2}$ analyzers use different wavelength to differentiate energy absorption by $\mathrm{CO}_{2}$ and $\mathrm{H}_{2} \mathrm{O}$. Understanding this, some companies have changed their product line (e.g. model 6251 changing to 6252 or 6262 , LI-COR, Lincoln, NE) to reflect this understanding and ensure that they offer products that account for both $\mathrm{CO}_{2}$ and $\mathrm{H}_{2} \mathrm{O}$ vapor in the gas stream.

Air speed around the canopy

Sufficient air movement in a chamber is desirable not only to promote air mixing to achieve a homogeneous environment but also to encourage gas exchange between a plant and its environment. Insufficient air movement around plants generally limits their growth by suppressing the gas diffusion in the leaf boundary layer, thereby decreasing Pn (Yabuki and Miyagawa, 1970). The optimum air velocities on the plant surface for the plant growth are 0.3 to $0.7 \mathrm{~m} \mathrm{~s}^{-1}$ (Wadsworth, 1959).

Special consideration is needed for the placement of circulation fans that are typically used to promote air composition homogeneity in the chamber. Since a fan creates a lower pressure zone behind when it moves air forward, one need to make sure its placement does not draw in any outside air.

Table 2 provides additional climate control information of various Open whole canopy photosynthesis systems.

\section{BIOLOGICAL FACTORS INFLUENCING PHOTOSYNTHESIS DETERMINATION}

Determination of CER is based on the measurement of $\mathrm{CO}_{2}$ dynamics. In addition to photosynthesis and respiration of the plant in the measurement system, other sources and sinks of $\mathrm{CO}_{2}$ in the measurement system should also be considered to improve the CER measurement accuracy. 


\section{N. TAKAHASHI ET AL.}

Table 2 Minimum guidelines of environmental control consideration of various Open systems.

\begin{tabular}{|c|c|c|c|c|}
\hline \multirow[b]{2}{*}{ References } & \multicolumn{4}{|c|}{ Mentioned factors } \\
\hline & $\begin{array}{l}\text { Air speed around } \\
\text { the plant }\end{array}$ & $\begin{array}{l}\text { Pressurized cham- } \\
\text { ber to prevent in- } \\
\text { ward air leakage }\end{array}$ & To adjust the Air flow rate & $\begin{array}{l}\text { Humidity } \\
\text { control }\end{array}$ \\
\hline $\begin{array}{l}\text { Bate and Canvin } \\
\qquad(1971)\end{array}$ & Not reported & Yes & $\begin{array}{l}\text { To maintain } \mathrm{CO}_{2} \text { differential } \\
\text { less than } 30 \mu \mathrm{mol} \mathrm{mol}^{-1}\end{array}$ & cooling coil \\
\hline Bugbee (1992) & $0.8 \mathrm{~m} \mathrm{~s}^{-1}$ & Yes & Not reported & desiccant \\
\hline $\begin{array}{c}\text { Corelli-Grappadelli } \\
\text { and Magnanini } \\
(1993)\end{array}$ & Not reported & Yes & $\begin{array}{l}\text { To regulate temperature in } \\
\text { the chamber }\end{array}$ & Not reported \\
\hline Miller et al. (1996) & Not reported & Yes & $\begin{array}{c}\text { To regulate temperature in } \\
\text { the chamber }\end{array}$ & Not reported \\
\hline $\begin{array}{l}\text { van Iersel and } \\
\text { Bugbee (2000) }\end{array}$ & Not reported & Yes & $\begin{array}{l}\text { To maintain } \mathrm{CO}_{2} \text { concentra- } \\
\text { tion in the chamber }\end{array}$ & cooling coil \\
\hline
\end{tabular}

\section{Soil respiration}

Respiration by microorganisms in the root zone consists of two separate processes, respiration of organic compounds leaking from plant roots and microbial breakdown of organic matter in the growing medium. van Iersel and Lindstrom (1999) pointed out that respiration resulting from the breakdown of organic products leaking from plant roots into the soil or growing medium was included in the whole plant photosynthesis measurements, because root respiration, in this case, used substrate that was originally derived from plant biological activity. The $\mathrm{CO}_{2}$ from microbial breakdown of soil organic matter, however, is not related to plant metabolism, thus could cause a significant error to the measurement if very small plants are grown in a large volume of soil (van Iersel and Bugbee, 2000). Measurements of roots and microbes on healthy plant roots indicate that the fraction of carbon respired by root zone microorganisms is typically less than $2 \%$ of total carbon fixed by plants (Højberg and Sørensen, 1993; Smart et al., 1995), or less than $0.1 \%$ of the daily carbon gain of typical plant canopies (van Iersel and Bugbee, 2000). To reduce root-zone $\mathrm{CO}_{2}$ contributions, the root zone can have a $\mathrm{pH}$ value of 4.8 or less to minimize dissolved carbon in solution (Bugbee, 1992). If desired, the CER measurement can be adapted to measure root-zone $\mathrm{CO}_{2}$ efflux separately (Monje and Bugbee, 1998).

\section{Irrigation}

Watering plants can affect $\mathrm{CO}_{2}$ concentration in a micro-environment. A decrease in photosynthesis was observed immediately after the plants were watered with nutrient solution (van Iersel and Bugbee, 2000). Water can contain significant amounts of biocarbonate, which can alter the $\mathrm{CO}_{2}$ absorption in the water, thereby changing the measured photosynthesis or respiration. It is suggested that $\mathrm{CO}_{2}$ evolution after watering can be minimized by adjusting the $\mathrm{pH}$ of the water to 5.5 or less.

\section{EVALUATION OF OPEN PHOTOSYNTHESIS MEASUREMENT SYSTEM}

To evaluate performance of a whole canopy carbon exchange system, a two-step evaluation procedure may be considered.

\section{CER measurement accuracy}

To verify measurement accuracy of a system, a known amount of $\mathrm{NaHCO}_{3}$ can be placed in the chamber and dilute acid is added at a slow rate. In the resulting reaction, 1 mole of $\mathrm{CO}_{2}$ is evolved from each mole of $\mathrm{NaHCO}_{3}$ as follows: 


$$
\mathrm{NaHCO}_{3}+\mathrm{H}^{+} \rightarrow \mathrm{Na}^{+}+\mathrm{H}_{2} \mathrm{O}+\mathrm{CO}_{2} \uparrow
$$

The system accuracy is given by comparing the measured CER with the known amount of $\mathrm{CO}_{2}$ evolution. van Iersel and Bugbee (2000) used this approach to evaluate performance of their Open system.

\section{Pn measurement accuracy}

To evaluate the whole canopy CER measurement system, the predicted carbon gain is compared with the carbon gain determined using a destructive method. The carbon gain is predicted using cumulative carbon gain $(\mathrm{CCG})$ determined from the $\mathrm{CO}_{2}$ exchange rate as follow:

$$
C C G=\int_{0}^{t}\left(P_{n, \text { avg }}+R_{\text {avg }}\right) d t
$$

where $P_{n, \text { avg }}$ is average Pn, $R_{\text {avg }}$ is average respiration, $t$ is the duration of the measurement. By multiplying CCG $\left(\mathrm{mol} \mathrm{m}^{-2}\right)$ by $12 \mathrm{~g} \mathrm{~mol}^{-1}$ for carbon, and dividing this by the measured carbon content (destructive tissue sampling required for measurement in a C-H-N analysis system), the final mass can be estimated, and then compared to the actual mass. If the gas exchange measurements were accurate, the slope of this comparison should be close to 1 with a high correlation.

\section{CONCLUSION}

Custom whole canopy CER measurement systems have been designed and constructed to assess integral responses of whole plants. While they have many advantages over commercially available leaf CER measurement systems, its construction, instrumentation and operation should be carefully considered for accurate photosynthesis measurements. Good correlations between CER, measured using the whole canopy system, accumulated over time and final yield have been reported. Relationships between short-term CER measurements and long-term yield remain inconclusive. Since 1989, $\mathrm{CO}_{2}$ probes as well as data acquisition systems have become less expensive yet more reliable. These improvements should make incorporating $\mathrm{CO}_{2}$ gas exchange as a standard laboratory technique more common, and it has on the single leaf or leaf part level. Whole plant gas exchange measurements remain uncommon, in part due to a lack of reliable, standardized system. The reduction of $\mathrm{CO}_{2}$ sensor cost has coincided with an increase in plant molecular tools and in spite of a few important studies that have integrated different measurement scales (Somerville, 2001), the use of whole-plant gas exchange techniques remains underused. Modern research topics such as global climate change, the need to integrate whole-plant effects of stress with molecular responses, and continued efforts on maximizing crop yield all require that accurate photosynthesis and respiration measurements should be evaluated and improved.

Funding of this project was partially supported by USDA/ARS Greenhouse Production Research Group, USDA/CSREES/Hydroponics Project, and Ohio Agriculture Reseach and Development Center.

\section{REFERENCES}

Acock, B., Acock, M. 1989. Calculation air leakage rates in controlled-environment chambers containing plants. Agron. J. 81: 619-623.

Amthor, J. S. 1994. Scaling $\mathrm{CO}_{2}$-photosynthesis relationships from the leaf to the canopy. Photosynthesis Res. 39: 321-351.

Aoki, M. 1997. Instrument and methodology for Agricultural Meteorology. (Japanese text) Nogyo Gizyutsu kyokai, Tokyo, p 297-321.

Baker, J. T., Kim, S. H., Gitz, D. C., Timlin, D., Reddy, V. R. 2004. A method for estimating carbon dioxide 


\section{N. TAKAHASHI ET AL.}

leakage rates in controlled-environment chambers using nitrous oxide. Environ. Exp. Bot. 51: 103-110.

Bate, G. C., Canvin, D. T. 1971. A gas-exchange system for measuring the productivity of plant populations in controlled environments. Can. J. Bot. 49: 601-608.

Boote, K. J., Loomis, R. S. 1991. The prediction of canopy assimilation. In "Modeling Crop Photosynthesisfrom Biochemistry to Canopy" (ed. by Boote, K., Loomis, R.), Crop Sci. Soc. Am. Spec. Pub., Madison, Wis., p 109-140.

Bugbee, B. 1992. Steady-state canopy gas exchange: System design and operation. HortScience 27: 770-776.

Coombs, J., Hall, D. O., Long, S. P., Scurlock, J. M. O. 1985. Techniques in bioproductivity and photosynthesis. Pergamon Press, Oxford.

Corelli-Grappadelli, L., Magnanini, E. 1993. A whole-tree system for gas-exchange studies. HortScience 28: 41-45.

Dutton, R. G., Jiao, J., Tsujita, M. J., Grodzinski, B. 1988. Whole plant exchange measurement for nondestructive estimation of growth. Plant Physiol. 86: 355-358.

Elmore, C. D. 1980. The paradox of no correlation between leaf photosynthetic rates and crop yields. In "Predicting Photosynthesis for Ecosystem Models" (ed. by Hesketh, J. D., Jones, J. W.), Vol. II, CRC Press, Boca Raton, FL., p 155-167.

Evans, L. T. 1993. Crop evolution, adaptation and yield. Cambridge Univ. Press, Cambridge.

Field, C. B., Ball, J. T, Berry, J. A. 1989. Photosynthesis: principles and field techniques. In "Plant Physiological Ecology: Field Methods and Instrumentation” (ed. by Pearcy, R. W., Ehleringer, J., Mooney, H. A., Rundel, P. W.), Chapman and Hall, London and New York, p 209-253.

Frantz, J. M., Cometti, N. N., Bugbee, B. 2004. Night temperature has a minimal effect on respiration and growth in rapidly growing plants. Ann. Bot. 94: 155-166.

Højberg, O., Sørensen, J. 1993. Microgradients of microbial oxygen consumption in a barley rhizosphere model system. Appl. Environ. Microbiol. 59: 431-437.

Katsura, K., Maeda, S., Horie, T., Shiraiwa, T. 2006. A multichannel automated chamber system for continuous measurement of carbon exchange rate of rice canopy. Plant Prod. Sci. 9: 152-155.

Kimball, B. A. 1990. Exact equations for calculating air leakage rates from plant growth chambers. Agron. J. 82: $998-1003$.

Klingeman, W. E., Buntin, G. D., van Iersel, M. W., Braman, S. K. 2000. Whole-plant gas exchange, not individual-leaf measurements, accurately assesses azalea response to insecticides. Crop Protection 19: 407415 .

Leonardos, E. D., Tsujita, M. J., Grodzinski, B. 1994. Net carbon dioxide exchange rates and predicted growth patterns in Alstroemerica 'Jacqueline' at varying irradiances, carbon dioxide concentrations, and air temperatures. J. Am. Soc. Hortic. Sci. 119: 1265-1275.

Long, S. P. 1985. Measurement of photosynthetic gas exchange. In "Techniques in Bioproductivity and Photosynthesis" (ed. by Coombs, J., Hall, D. O., Long, S. P., Scurlock, J. M. O.), Pergamon Press, Oxford, p 25-36.

Miller, D. P., Howell, G. D., Flore, J. A. 1996. A whole-plant, gas-exchange system for measuring net photosynthesis of potted woody plants. HortScience 31: 944-946.

Mitchell, C. A. 1992. Measurement of photosynthetic gas exchange in controlled environments. HortScience 27: $764-767$.

Monje, O., Bugbee, B. 1998. Adaptation to high $\mathrm{CO}_{2}$ concentration in an optimal environment: radiation capture, canopy quantum yield, and carbon use efficiency. Plant Cell Environ. 21: 315-324.

Norman, J. M., Arkebauer, T. J. 1991. Predicting canopy photosynthesis and light-use efficiency from leaf characteristics. In "Modeling Crop Photosynthesis-from Biochemistry to Canopy" (ed. by Boote, K., Loomis, R.), Crop Sci. Soc. Am. Spec. Pub., Madison, Wis., p 75-94.

Pena, J. P., Terara, J. 2004. A portable whole canopy gas exchange system for several mature field-grown grapevines. Vitis 43: 7-14.

Penning de Vries, F. W. T., Akkersdijk, J. W. J., van Oorschot, J. L. P. $1984 . \quad$ An error in measuring respiration and photosynthesis due to transpiration. Photosynthetica 18: 146-149.

Poni, S., Magnanini, E., Rebucci, B. 1997. An automated chamber system for measurements of whole-vine gas exchange. HortScience 32: 64-67.

Samish, Y. B. 1978. Measurement and control of $\mathrm{CO}_{2}$ concentration in air is influenced by the desiccant. Photosynthetica 12: 73-75.

Šesták, Z., Čatský, J., Jarvis, P. G. 1971. Plant photosynthetic production: Manual and methods, The Hague, 


\section{PHOTOSYNTHESIS MEASUREMENT}

Junk.

Smart, D. R., Ferro, A., Ritchie, K., Bugbee, B. $\quad 1995$. On the use of antibiotics to reduce rhizoplane microbial populations in root physiology and ecology investigations. Physiol. Plant. 95: 533-540.

Somerville, C. R. 2001. An early Arabidopsis demonstration. Resolving a few issues concerning photorespiration. Plant Physiol. 125: 20-24.

Terashima, I., Wong, S. C., Osmond, C., Farquhar, G. 1988. Characterization of nonuniform photosynthesis inducted by abscisic acid in leaves having different mesophyll anatomies. Plant Cell Physiol. 29: 385-394.

Tingey, D. T., Waschmann, R. S., Phillips, D. L., Olszyk, D. M. 2000. The carbon dioxide leakage from chambers measured suing sulfur hexafluoride. Environ. Exp. Bot. 43: 101-110.

van Iersel, M. W., Bugbee, B. 1997. Dibutylurea reduces photosynthesis, growth, and flowering of petunia and impatients. J. Am. Soc. Hortic. Sci. 122: 536-541.

van Iersel, M. W., Bugbee, B. 2000. A multiple chamber, semicontinuous, crop carbon dioxide exchange system: Design, calibration, and data interpretation. J. Am. Soc. Hortic. Sci. 125: 86-92.

van Iersel, M. W., Lindstrom, O. M. 1999. Temperature response of whole-plant $\mathrm{CO}_{2}$ exchange rates of three magnolia cultivars. J. Am. Soc. Hortic. Sci. 124: 277-282.

Wadsworth, R. M. 1959. An optimum wind speed for plant growth. Ann. Bot. 23: 195-199.

Wheeler, R. M. 1992. Gas-exchange measurements using a large, closed plant growth chamber. HortScience 27: $777-780$.

Wheeler, R. M., Sager, J. C., Prince, R. P., Knott, W. M., Mackowiak, C. L., Stutte, G. W., Yorio, N. C., Ruffe, L. M., Peterson, B. V., Goins, G. D., Hinkle, C. R., Berry, W. L. 2003. Crop production for advanced life support systems. NASA TM211184.

Whiting, M. D., Lang, G. A. 2001. Canopy architecture and cuvette flow patterns influence whole canopy net $\mathrm{CO}_{2}$ exchange and temperature in sweet cherry. HortScience 36: 691-698.

Yabuki, K., Miyagawa, H. 1970. Studies on the effect of wind speed on photosynthesis. J. Agric. Meteorol. 26: $137-142$.

Zelitch, I. 1982. The close relationship between net photosynthesis and crop yield. Bioscience 32: 796-802. 